\title{
Estimativa da radiação fotossinteticamente ativa absorvida pela cultura da soja através de dados do sensor Modis
}

\author{
Denise Cybis Fontana ( $\left.{ }^{1 *}\right)$; Gilca Marques Alves ( $\left.{ }^{1}\right)$; Debora Roberti ( $\left.{ }^{2}\right)$; \\ Osvaldo Luiz Leal de Moraes ( $\left.{ }^{2}\right)$; Anderson Gerhardt ( $\left.{ }^{1}\right)$ \\ (') Universidade Federal do Rio Grande do Sul (UFRGS), Departamento de Plantas Forrageiras e Agrometeorologia, 91540-000 \\ Porto Alegre (RS), Brasil. \\ (2) Universidade Federal de Santa Maria (UFSM), Departamento de Física, 97105-900 Santa Maria (RS), Brasil. \\ (*) Autor correspondente: dfontana@ufrgs.br
}

Recebido: 14/maio/2012; Aceito: 12/out./2012

\begin{abstract}
Resumo
O objetivo deste trabalho foi testar um método de geração de informações da distribuição espacial e temporal da radiação fotossinteticamente ativa absorvida (RFAa), pela cultura da soja, a partir da quantificação da relação entre o índice de vegetação por diferença normalizada (NDVI) e a fração da radiação fotossinteticamente ativa absorvida (FRFAa) pela cultura. O estudo abrangeu o município de Cruz Alta, um dos grandes produtores de soja do Rio Grande do Sul, durante duas safras: 2008/2009 e 2009/2010. Os dados de radiação fotossinteticamente ativa incidente (RFAi) foram monitorados em área experimental e os dados orbitais, provenientes de duas plataformas: Landsat/TM e Terra/MODIS, ambos com distribuição gratuita, mas com características distintas. Foi estabelecida uma relação linear simples entre o NDVI das imagens MODIS e a FRFAa obtida em dois períodos importantes do ciclo, semeadura e máximo desenvolvimento das plantas. Pelos resultados, observou-se que existe associação entre o NDVI e FRFAa, a qual pode, portanto, ser usada na geração de informações da RFAa pela cultura da soja ao longo do ciclo de desenvolvimento, permitindo, assim, um monitoramento temporal deste elemento.

Palavras-chave: NDVI, Glycine max, correlação.
\end{abstract}

\section{Estimation of the absorbed photosynthetically active radiation by the soybean crop through modis sensor data}

\section{Abstract}

The objective of this study was to test a methodology of data generation of the spatial and temporal distribution of the absorbed photosynthetically active radiation (RFAa) by the soybean crop based on the quantification of the relation between the normalized difference vegetation index (NDVI) and the fraction of absorbed photosynthetically active radiation (FRFAa) by the crop. The study covered the county of Cruz Alta, one of the largest producers of soybean in Rio Grande do Sul, Brazil, during the period of two harvest seasons: 2008/09 and 2009/10. The data of the incident photosynthetically active radiation (RFAi) were collected on the experimental area and the orbital data came from two platforms: Landsat/TM and Terra/MODIS, both with free distribution, but with distinct characteristics. A simple linear relation was established between the NDVI of the MODIS images and the FRFAa, obtained during two important periods of the cycle: sowing and maximum plant growth. The results showed that there is an association between the NDVI and the FRFAa that can, therefore, be used on the generation of RFAa data by the soybean crop throughout the development cycle, allowing the temporal monitoring of this element.

Key words: NDVI, Glycine max, correlation. 


\section{INTRODUÇÃO}

O Rio Grande do Sul tem sua economia fortemente baseada na atividade agrícola, sendo a soja a cultura de maior expressão, ocupando uma área aproximada de 3,72 milhōes hectares (IBGE, 2011), contribuindo fortemente para o PIB do Estado. Em vista da importância desta cultura, é crescente a necessidade da geração de informaçóes que possam servir de subsídios tanto para programas de previsão de safras, como para análise do impacto ambiental deste cultivo.

Em termos de previsão de safras, estão disponíveis modelos de estimativa de rendimento, usando diferentes enfoques teóricos. Para a cultura da soja, existem já ajustados para o Rio Grande do Sul desde os modelos de simulação do crescimento e desenvolvimento, que utilizam diversas informaçóes como variáveis de entrada (Martorano et al., 2008), até modelos agrometeorológicos, que em geral consideram somente a disponibilidade hídrica (Fontana et al., 2001). Qualquer que seja o enfoque do modelo, na maior parte das vezes, especialmente em estudos regionais, a disponibilidade dos dados de entrada dos modelos é menor do que a necessária para representar de forma adequada a variabilidade espacial.

Quanto ao impacto ambiental do cultivo de soja, apesar do crescente interesse da comunidade científica, ainda são escassos os trabalhos publicados no Brasil com mediçôes consistentes e continuadas relacionadas, por exemplo, às trocas de dióxido de carbono $\left(\mathrm{CO}_{2}\right)$ entre a superfície ocupada com a cultura da soja e a atmosfera (Webler et al., 2012). Além disso, a maior parte destes trabalhos realiza medidas das trocas de $\mathrm{CO}_{2}$ de forma pontual utilizando torres micrometeorológicas, sendo um desafio à extrapolação destas medições para o nível regional.

Uma forma de representar espacialmente a variabilidade dos rendimentos ou estender as estimativas de trocas de $\mathrm{CO}_{2}$ para uma escala espacial mais abrangente, representando a diversidade de classes de uso e cobertura da terra, é o uso do sensoriamento remoto como estimador de alguns dos parâmetros necessários aos modelos. Em vista da relação existente entre o índice de vegetação por diferença normalizada (NDVI) e a biomassa verde (BARET e GuYot, 1991), este índice tem sido empregado tanto na estimativa de rendimento, através dos modelos agrometeorológicos espectrais (Rizzi e RudorfF 2007; Melo et al., 2008), como dos fluxos de $\mathrm{CO}_{2}$ entre a superfície e a atmosfera através de relaçóes diretas ou mesmo como estimador de parâmetros utilizados na modelagem dos fluxos gasosos (Olfsson e EkLundh, 2007; Schubert et al., 2010; Sృöström et al., 2011).

Em qualquer destas análises, o conhecimento do acúmulo de biomassa através do processo fotossintético é uma exigência, o qual está fortemente relacionado à absorção de radiação pelas plantas em comprimentos de ondas do visível $(0,4$ a $0,7 \mu \mathrm{m})$, faixa conhecida como radiação fotossinteticamente ativa $(R F A)$. Entretanto, somente parte da RFA incidente é absorvida e aproveitada no processo fotossintético. A estimativa da RFA absorvida $(R F A a)$ pelas plantas é, portanto, parâmetro necessário à modelagem do crescimento das plantas, sendo determinada pelo balanço entre a radiação recebida subtraindo as fraçôes transmitidas e refletidas para o meio.

A RFAa pode ser estimada pelo produto da $R F A$ incidente $(R F A i)$ pela fração de radiação fotossinteticamente ativa absorvida (FRFAa) pelas plantas, ou seja, $R F A a=R F A i^{*} F R F A a$ (Kumar e Monteith, 1981). Este último parâmetro representa a eficiência com que a planta absorve a $R F A i$ sobre o dossel, a qual é variável ao longo do ciclo e das condiçôes de crescimento e desenvolvimento das plantas. À medida que aumenta o índice de área foliar $(I A F)$, aumenta a eficiência de absorção da $R F A$, sendo a forma da relação dependente da estrutura do dossel. No Rio Grande do Sul, para a cultura da soja, Martorano et al., (2008) observou que a eficiência de absorção no início do ciclo é baixa, cerca de 4\%, e aumenta até atingir o valor máximo de $95 \%$ no máximo $I A F$, que foi de 6,3. Máximo desta magnitude tem sido observado para culturas anuais (França et al., 1999; Radim et al., 2003; Muller e BERgAMASCHI, 2005).

Uma adequada representação da variabilidade espacial da RFAa pode ser obtida utilizando sensores remotos e quantificando, para diferentes ambientes, a relação entre o NDVI e a FRFAa (Justice, 1986; Barret e Guyot, 1991; Sellers et al., 1994; Moreira et al., 2005; Olofsson et al., 2007). Os mapas de $R F A a$ produzidos a partir desta relação podem indicar a variabilidade espacial e evolução temporal da cobertura vegetal para grandes áreas e períodos de tempo e, em particular, podem indicar áreas de maior atividade da vegetação e que contribuem na retirada de carbono atmosférico, além de possibilitar o monitoramento do rendimento.

O NDVIobtido a partir de imagens do sensor MODIS (Moderate Resolution Imaging Spectroradiometer), produto MOD13Q1, neste contexto é uma possibilidade promissora. Este produto possui características apropriadas a este tipo de estudo, causadas pela resolução temporal de 16 dias, propiciando adequada representação da variabilidade da biomassa ao longo do ciclo, e resolução espacial de $250 \mathrm{~m}$, o que permite uma representaçáo espacial compatível com o tamanho de lavouras de soja no Estado do Rio Grande do Sul.

O objetivo deste trabalho foi testar um método de geração informaçôes da distribuição espacial e temporal da radiação fotossinteticamente ativa absorvida $(R F A a)$ pela cultura da soja a partir da quantificação da relação entre o NDVI e a FRFAa. 


\section{MATERIAL E MÉTODOS}

\section{Caracterização da área experimental e dos dados de campo}

O estudo abrangeu o município de Cruz Alta (Figura 1), um dos grandes produtores de soja do Estado, localizando na metade norte do Rio Grande do Sul. A atividade agrícola no município é intensa, predominando as culturas de soja e milho no período de primavera-verão, as quais podem ser identificadas na composição colorida da imagem Landsat/TM da área de estudo do dia 21 de janeiro de 2009, associadas aos tons amarelo e verde. Neste estudo, foram avaliadas as safras: 2008/2009 e 2009/2010, somente para a cultura da soja, cultura que ocupa maior área. Neste município, a área média cultivada com soja nos dois anos analisados foi próxima de 80.000 ha, cerca de 10 vezes maior do que a área cultivada com o milho (IBGE, 2011).

Os dados de superfície foram coletados pela equipe do Laboratório de Micrometeorologia, localizado em Santa Maria (RS). O talhão experimental, oriundo de um experimento de longa duração, com dimensão de 40x60 m, foi semeado com a cultivar de soja FUNDACEP 53 RR e desenvolvido em sistema de plantio direto (esta área experimental esta situada em uma grande área agrícola, maior que 200 hectares), com espaçamento entrelinhas de $0,40 \mathrm{~m}$. No centro do talhão foi instalada uma torre medidora de fluxos turbulentos (coordenadas -28 $8^{\circ} 36^{\prime} 02^{\prime \prime}$; $-53^{\circ} 40^{\prime} 18^{\prime \prime}$ ), pertencente ao projeto Sulflux (Sulflux, 2012) e equipada com sensores de alta frequência. Do conjunto de dados coletados, neste trabalho, foram usados somente os oriundos do sensor de radiaçáo fotossinteticamente ativa incidente - RFAi (PAR LITE, instalado a uma altura de $1 \mathrm{~m}$ ). Os dados brutos foram armazenados em tempo real, depois calculadas as médias para intervalos de 30 minutos (redução do volume de dados) e, posteriormente, organizados em valores médios diários de RFAi para a média do período de 16 dias, compatibilizando com a escala temporal das imagens MODIS. Na elaboração da média dos 16 dias, foram utilizados somente os períodos com mais de 10 dias úteis de observações, em decorrência de falhas de leituras em diversos dias ao longo das duas safras analisadas. Na safra 2008/2009 foram passíveis de análises somente quatro períodos médios de 16 dias.

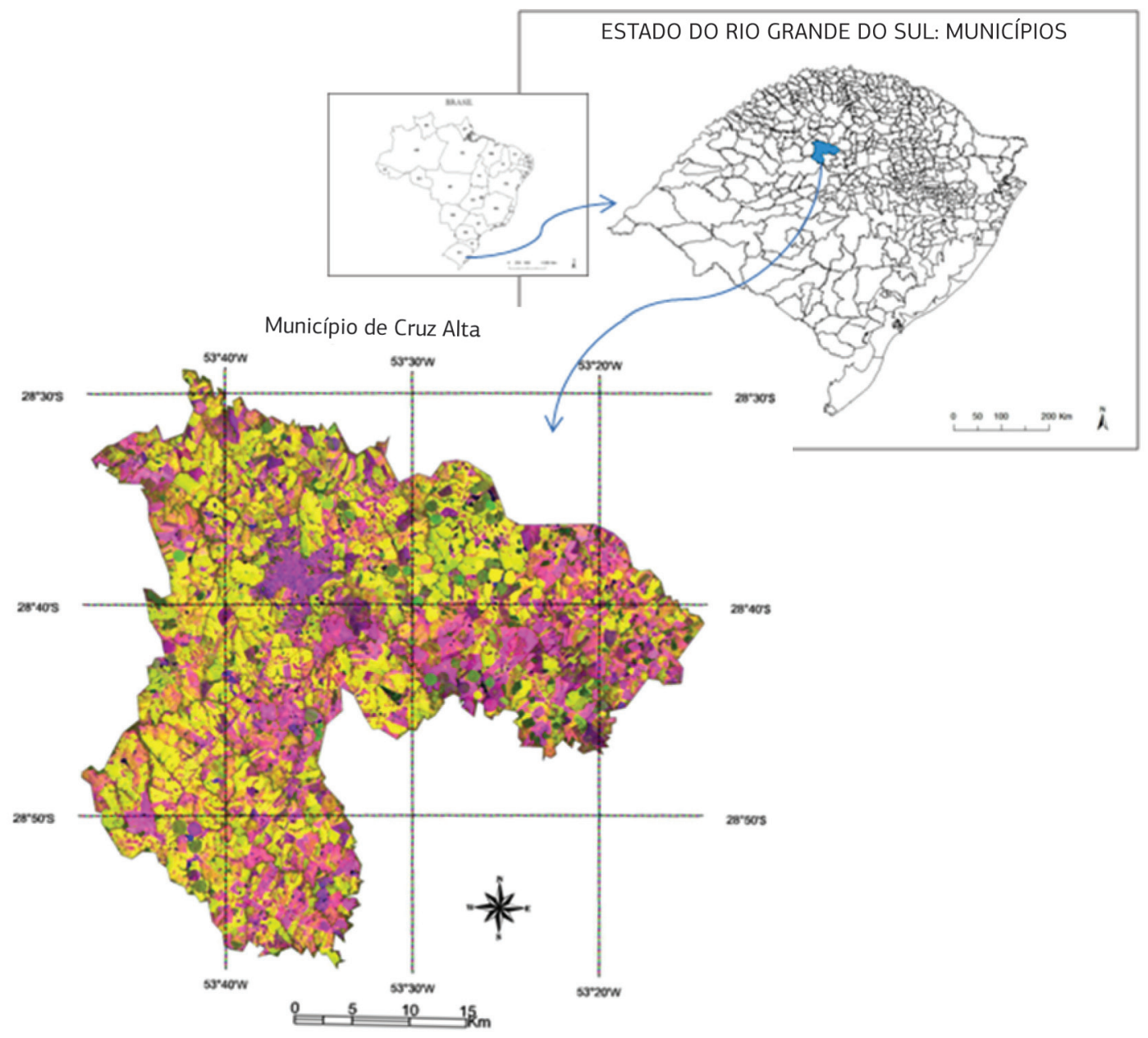

Figura 1. Imagem Landsat/TM, composição colorida RGB 543, de 21/1/2009 do município de Cruz Alta, Rio Grande do Sul. 


\section{Dados de sensoriamento remoto}

Os dados orbitais foram provenientes de duas plataformas: Landsat/TM e Terra/MODIS, ambas com distribuição gratuita (INPE, 2011; NASA, 2011), mas com características distintas. As imagens Landsat/TM, com resolução espacial de $30 \mathrm{~m}$ e resolução temporal de 16 dias foram usadas para a construçáo da máscara de cultivo das áreas ocupadas com soja em todo o município de estudo. Destas imagens, foi extraído o NDVI médio de todos os pixels que cobrem as áreas cultivadas com soja em Cruz Alta para cada data e safra analisada.

As imagens Terra/MODIS, referentes ao produto MOD13Q1 (Huete et al., 2002), que são disponibilizadas com resolução espacial de $250 \mathrm{~m}$ e resolução temporal de 16 dias (composiçấo de máximo valor do índice no período), foram usadas para o monitoramento da evolução temporal do $N D V I$ das lavouras de soja do município ao longo do ciclo da cultura da soja (novembro a abril). Em cada safra, ao longo do ciclo da soja foram adquiridas 12 imagens MODIS, ao passo que somente cinco e duas imagens Landsat/TM respectivamente, nas safras 2008/2009 e 2009/2010.

Inicialmente, foi feita uma análise de comparativa dos dados NDVI das imagens Landsat/TM e Terra/MODIS de toda a área cultivada com soja no município. Foi calculada a correlação entre os dados dos dois sensores utilizando as datas coincidentes nas duas safras. Em segunda análise, foi estabelecida uma relação linear entre o $N D V I$ das imagens MODIS e a fração da radiação fotossinteticamente ativa absorvida (FRFAa) pelas lavouras de soja, na adaptação do método proposto por Olofsson e EKLUNdH (2007). Para o estabelecimento desta relação, foi feita a análise do histograma das imagens MODIS (Figura 2) e extraído o valor de $N D V I$ correspondente a $5 \%$ na distribuição de frequência acumulada em novembro $\left(N D V I_{\min }\right)$, o qual

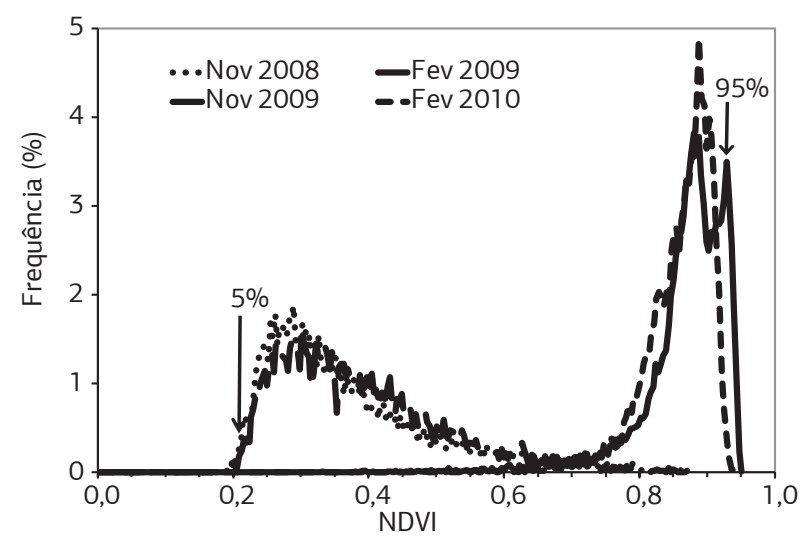

Figura 2. Histograma das imagens de NDVI da cultura da soja em novembro e em fevereiro nas safras 2008/2009 e 2009/2010 no município de Cruz Alta. As setas verticais indicam o valor de NDVI correspondente a 5\% (novembro) e 95\% (fevereiro) de frequência acumulada. concentra a semeadura da cultura, e o valor de $N D V I$ correspondente a $95 \%$ em fevereiro $\left(N D V I_{\text {max }}\right)$, quando ocorre o máximo desenvolvimento das plantas de soja. Os valores de NDVI mínimo e máximo tiveram valores semelhantes nas duas safras, sendo, respectivamente, 0,231 e 0,936 em 2008/2009 e 0,239 e 0,913 em 2009/2010. Para a semeadura, assumiu-se $F R F A a=0,1$ (baixíssima atividade da vegetação) e para o máximo desenvolvimento, $F R F A a=0,95$ (máximo de atividade da vegetação), segundo Olofsson e EkLundh (2007). Desta função, obteve-se o coeficiente angular da reta de regressão $(b)$ forçando a passagem pela origem (Figura 3). A construção da imagem de FRFAa para cada data nas duas safras foi feita baseada na equação 1 (Olofsson e EKLundh, 2007) e aplicada às imagens MODIS:

$$
F R F A a_{i, j}=b\left(\frac{N D V I_{I_{i, j}}-N D V I_{\text {min }}}{N D V I_{\text {max }}-N D V I_{\text {min }}}\right)
$$

em que: FRFAa é a fração de radiação fotossinteticamente ativa absorvida; $N D V I$ é o índice de vegetação por diferença normalizada; $(i, j)$ é a coordenada do pixel; $(\max )$ e $(\min )$ representam os pixels de maior e menor valor de NDVI respectivamente; $b$ é o coeficiente angular da reta de regressão linear $(b=0,99$ na Figura 2$)$.

A partir de FRFAa (Equaçáo 1) e da RFAi (medida na área experimental - assumida neste trabalho como constante em toda a cena), foi obtida a imagem de radiação fotossinteticamente ativa absorvida (RFAa), dada pela Equação 2:

$R F A a_{i, j}=F R R A a_{i, j}{ }^{*} R F A i$

Os valores médios de todos os pixels que cobrem as áreas com soja no município de Cruz Alta, obtidos das imagens de NDVI, FRFAa e de RFAa, foram representados na forma de imagens e também plotados para o período de novembro a abril, em intervalos de 16 dias, para ambas as safras.

\section{RESULTADOS E DISCUSSÃO}

A associação entre o valor do NDVI médio de todos os pixels que compóem a área cultivada com soja obtido das imagens Landsat/TM e das imagens Terra/MODIS é apresentada na figura 4. Apesar de neste trabalho não ter sido feita a avaliação da acurácia da máscara utilizada para a identificação das áreas de soja, assumiu-se, com base nos resultados de Gusso et al. (2012), que o método é confiável e gera um mapeamento adequado para fins de monitoramento de áreas agrícolas.

Observou-se para as duas safras que os valores de NDVI obtidos pelos dois sensores foram próximos e mostraram tendência similar, com um coeficiente de 


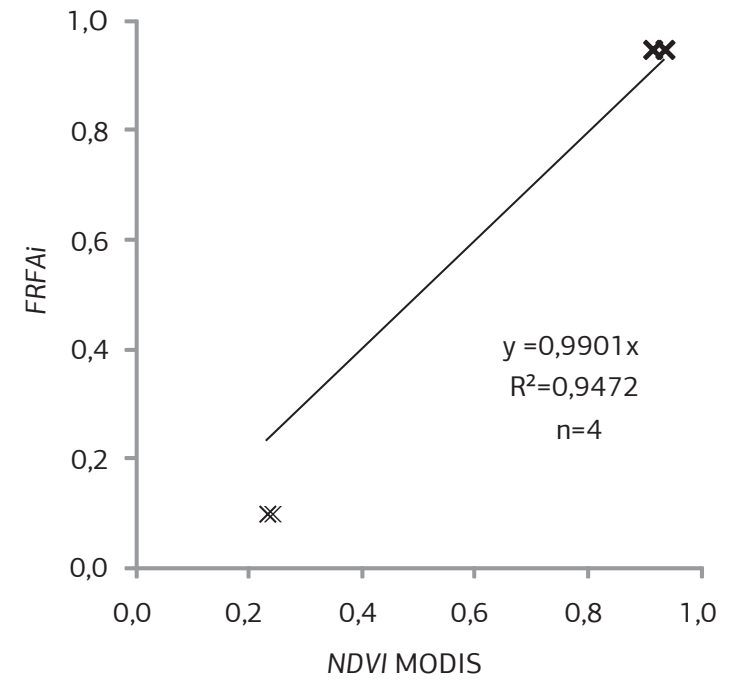

Figura 3. Relação entre o Índice de vegetação por diferença normalizada (NDVI), obtido em imagens MODIS, e a fração da radiação fotossinteticamente ativa interceptada (FRFAi) pela cultura da soja em Cruz Alta, nas safras 2008/2009 e 2009/2010.

correlação de 0,964. Em vista da confiabilidade já estabelecida das informaçóes Landsat/TM, evidencia-se que as imagens Terra/MODIS podem ser utilizadas para monitorar a cultura da soja do município de Cruz Alta, tendo a vantagem de apresentar uma frequência temporal compatível à dinâmica destas lavouras.

No perfil temporal do NDVI das áreas cultivadas com soja neste município (Figura 5), em ambas as safras, observou-se o padrão esperado para lavouras anuais, o que já foi apontado em estudos anteriores (RIzZi e RUDORFF, 2007; Melo et al, 2008). Os valores foram baixos no início do ciclo, associados à baixa densidade de biomassa verde, crescentes até as lavouras atingirem o máximo crescimento e decrescentes depois, em função da senescência das plantas. Entretanto, verificaram-se diferenças neste padrão entre as duas safras avaliadas. Em 2008/2009 todo o ciclo da cultura foi mais tardio em relação a 2009/2010, o que foi coerente com a menor disponibilidade hídrica no período de desenvolvimento vegetativo na primeira safra. Associado a esta menor disponibilidade hídrica, os rendimentos em 2008/2009 foram menores (2200 $\mathrm{kg} \mathrm{ha}^{-1}$ ) do que em 2009/2010 (2400 kg ha $\left.{ }^{-1}\right)$, segundo IBGE (2011). Apesar disso, os valores médios, mínimos e máximos em ambas as safras foram semelhantes.

Apesar de maior detalhamento espacial (pixel de $30 \mathrm{~m}$ ), as imagens Landsat/TM revelaram um limitador temporal. $\mathrm{O}$ menor número de imagens Landsat/TM decorreu principalmente da presença de nuvens sobre a área experimental no momento da passagem do satélite, o que tem sido indicado como a principal limitação do uso deste sensor em diversas aplicaçóes com safras agrícolas (Sugawara et al., 2007). Assim, mesmo com resolução espacial de $250 \mathrm{~m}$, o que confere menor detalhamento

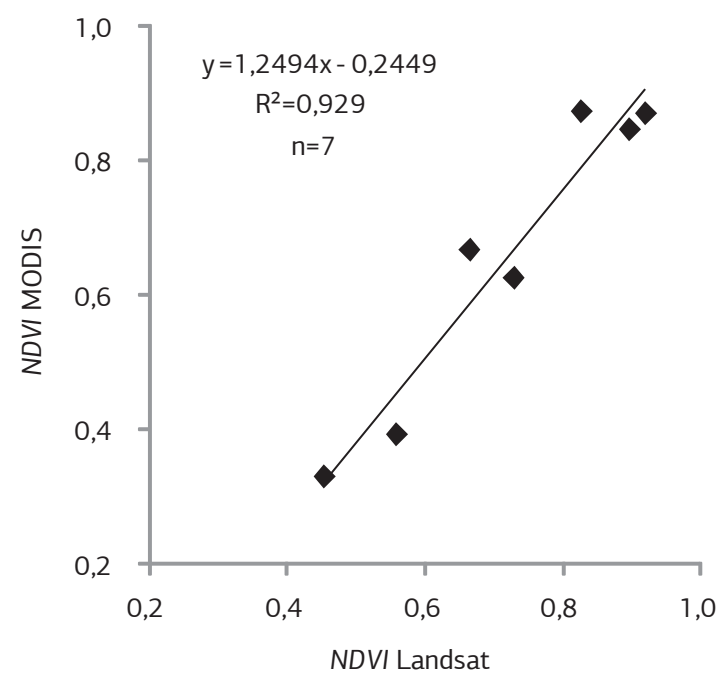

Figura 4. Relação entre o NDVI obtido a partir de imagens Landsat e imagens MODIS, nas áreas cultivadas com soja no município de Cruz Alta, nas safras 2008/2009 e 2009/2010.

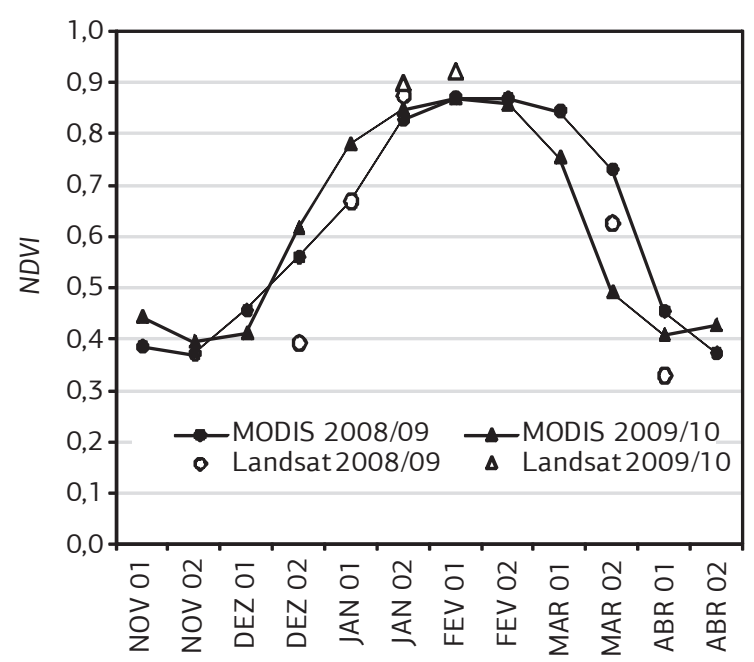

Figura 5. Índice de vegetação por diferença normalizada (NDVI) médio da área cultivada com soja no município de Cruz Alta nas safras 2008/2009 e 2009/2010, obtido de imagens Landsat/TM (símbolos vazados) e Terra/MODIS (símbolos preenchidos).

espacial, as imagens MODIS contêm características interessantes para o monitoramento da evolução de lavouras. Este produto tem sido muito utilizado e apontado como um dos mais interessantes conjuntos de informaçóes para estudos de monitoramento da vegetação global (Huete et al., 2002; Rosemback et al., 2010).

O histograma das imagens de NDVI (Figura 2) mostra a semelhança de padrão nas duas safras e também a diferença de valores observados nos pixels que compóem a área cultivada com soja em Cruz Alta, especialmente em relação ao início de ciclo (novembro) e ao máximo 
desenvolvimento (fevereiro). Em novembro, observou-se que as curvas estavam centradas em valores baixos de NDVI (menores do que 0,45) e em fevereiro ocorreu deslocamento em direçáo a altos valores (maiores do que $0,85)$, o que é coerente com calendário agrícola da cultura (Melo et al., 2008). A semelhança entre as duas safras pode ser o indicativo de estabilidade do parâmetro $b$ (intercepto) utilizado na Equação 1, o que deve ser ainda confirmado a partir da ampliação do número de anos avaliados, assim como para outras regióes de cultivo. Caso este fato se confirme, o método poderia ser utilizado em programas operacionais de monitoramento das lavouras de soja no Rio Grande do Sul.

A partir da distribuiçáo espacial de $F R F A a$, para três períodos importantes do ciclo da cultura nas duas safras (Figura 6), ou seja: novembro (estabelecimento das lavouras), janeiro (máximo incremento de biomassa verde) e fevereiro (máximo acúmulo de biomassa verde), verifica-se que no período de estabelecimento das lavouras, durante novembro, a fração absorvida da RFAi foi menor do que $30 \%$. No período de máximo incremento de biomassa verde (janeiro), $70 \%$ a $80 \%$ da $R F A i$ foi absorvida pelas lavouras de soja. No pico de acúmulo de biomassa verde (fevereiro), a FRFAa atingiu cerca de $90 \%$ da $R F A i$, sendo, portanto, o período de maior eficiência da cultura. Os valores aproximam-se dos registrados em experimentos em superfície para soja na região da Depressão Central do Rio Grande do Sul (Martorano et al., 2008), o que mostra a confiabilidade do método utilizado nesta análise. Já utilizando imagens orbitais, Oliveira e França (2011) estimou a FRFAa de diferentes tipos de cobertura vegetal no Brasil, usando imagens de NDVI do sensor AVHRR/

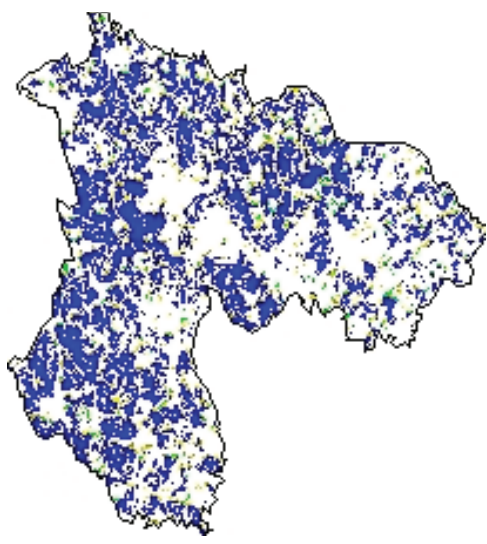

NOV 2008

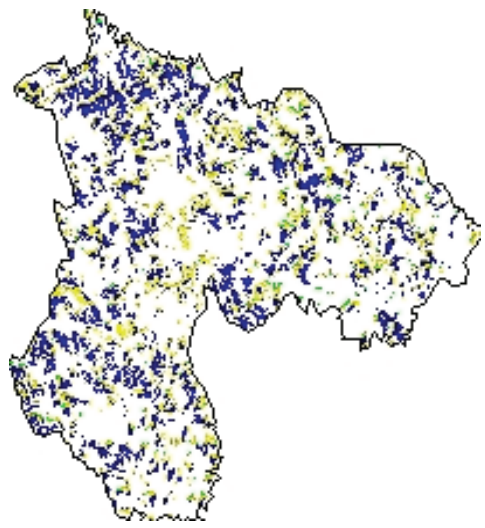

NOV 2009

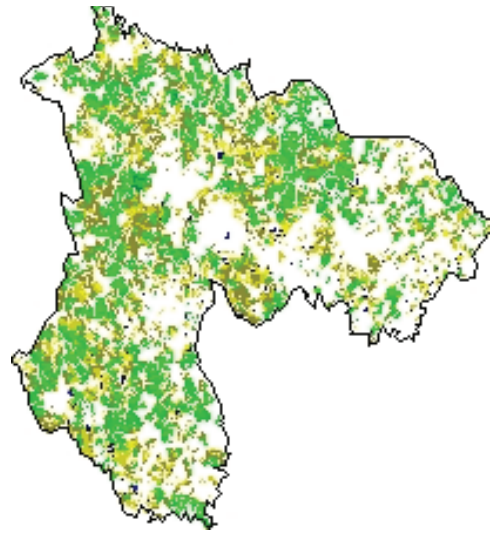

JAN 2009

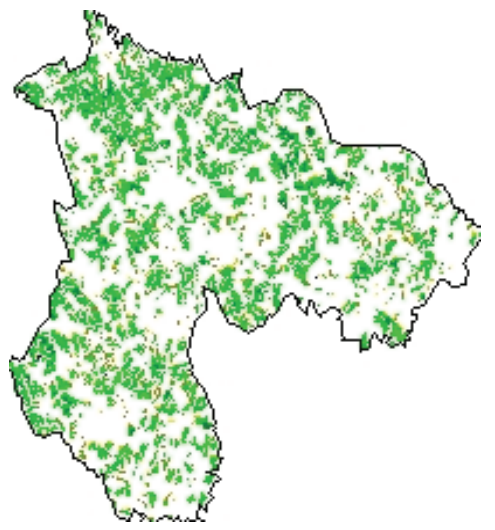

JAN 2010

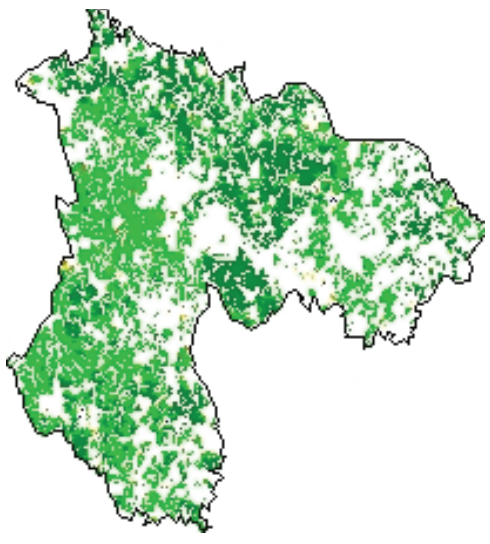

FEV 2009

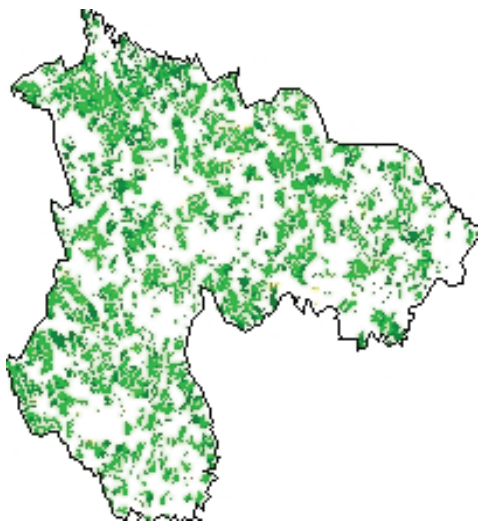

FEV 2010

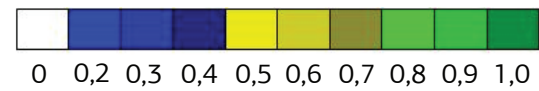

Figura 6. Imagens da média mensal da fração da radiaçâo fotossinteticamente ativa absorvida (FRFAa expressa em \%) pelas lavouras de soja no município de Cruz Alta, nas safras de 2008/2009 e 2009/2010. 
NOAA, obtendo valores médios que variaram de $55 \%$ em vegetação de savana a $79 \%$ em floresta ombrófila densa, com variação temporal associada à dinâmica da vegetação. Salienta-se que as limitaçôes do método de obtenção da FRFAa usando sensores orbitais estão associadas tanto às características do sensor (resoluçóes espacial e temporal) quanto às da área monitorada (diversidade de tipos vegetais e sua dinâmica), o que vai definir o grau de mistura espectral contida no pixel, assim como, a capacidade de monitoramento.

Verificou-se que o padrão de distribuição espacial da FRFAa foi semelhante nas duas safras (Figura 6), com baixa variabilidade espacial em cada uma das datas analisadas no município de estudo. Este fato, possivelmente, esteja associado à relativa homogeneidade das lavouras, consequência da estreita faixa de tempo recomendada à semeadura no município, de 21 de outubro a 31 de dezembro (MAPA, 2012), com maior concentraçáo em início de novembro. A possibilidade de análise da variabilidade espacial da FRFAa é uma das grandes contribuiçôes deste estudo, visto que em geral há a disponibilidade somente de medições que representam uma pequena área. Salienta-se que tais mediçôes são fundamentais para testes de metodologias alternativas e/ou complementares.

Na curva de FRFAa (Figura 7), nota-se uma evolução contínua, com padrão semelhante à evolução temporal do $N D V I$ (Figura 5), o que é esperado em vista da relação linear entre ambos. Na safra 2008/2009 (Figura 7a), em função dos problemas de medição e/ou registro da informação de RFAi em diversos períodos, a análise da variação ao longo do ciclo ficou comprometida. Para a safra 2009/2010 (Figura 7b), em razão do maior número de observaçóes, foi possível verificar a tendência sazonal deste elemento associada principalmente à declinação solar (definiçấo da densidade de fluxo de radiação incidente) e condiçôes de transparência atmosférica (definição das reduçôes ocorridas em janeiro e fevereiro devido à nebulosidade).

Os valores médios diários do período de 16 dias estimados RFAa para o município de Cruz Alta oscilaram de $40 \mathrm{~W} \mathrm{~m}^{-2}$ no início do ciclo a cerca de $160 \mathrm{~W} \mathrm{~m}^{-2}$ em fevereiro, quando a cultura estava com o máximo acúmulo de biomassa verde. A magnitude e a variabilidade de RFAa estimada ao longo do ciclo é comparável aos valores medidos em experimentos de superfície sobre culturas anuais cultivadas no período de primavera-verão (França et al., 1999; Müller et al., 2005). Ao dimensionar a $R F A a$ de uma lavoura específica, ou mapear a $R F A a$ por toda a área cultivada com soja em um município, se torna possível, por exemplo, fazer o cálculo da matéria seca acumulada, considerando a eficiência da planta em converter a energia absorvida. Segundo Martorano et al. (2008), a eficiência de conversão da radiação da soja depende da disponibilidade hídrica, mas varia de 1,57 a $0,90 \mathrm{~g}$ de matéria seca por MJ de $R F A a$, quando cultivada

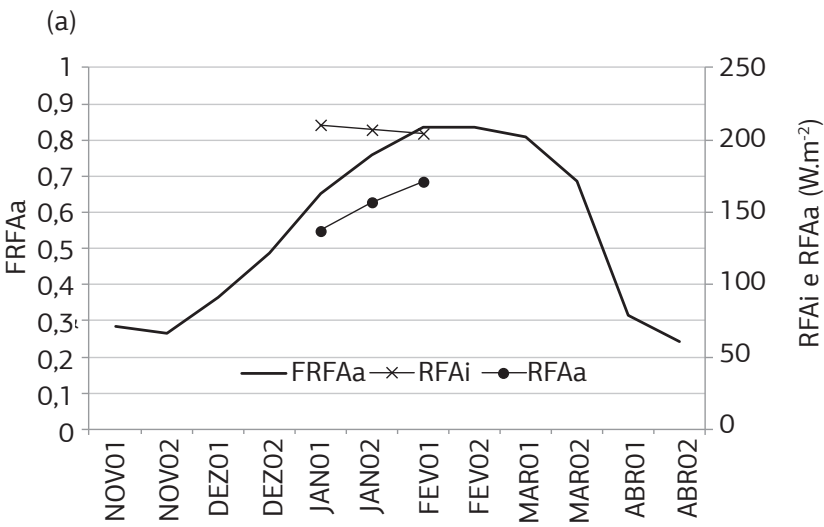

(b)

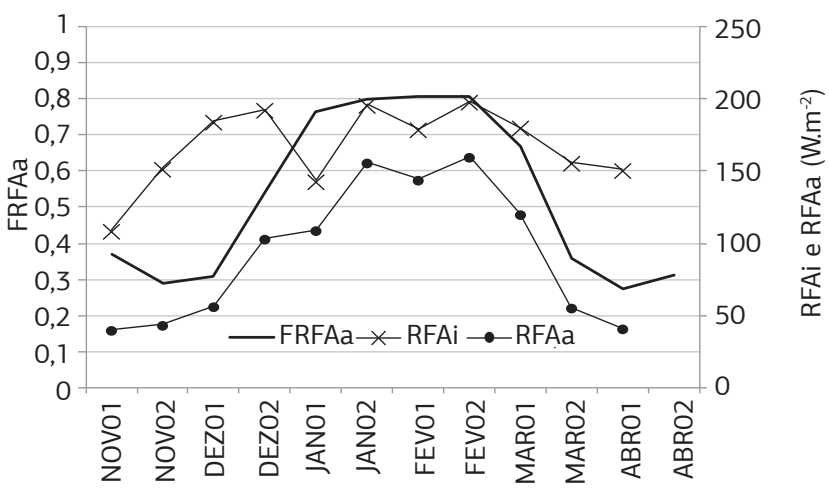

Figura 7. Evolução temporal da média diária no período de 16 dias da radiação fotossinteticamente ativa incidente (RFAi), da fração de radiação fotossinteticamente ativa absorvida (FRFAa) e radiação fotossinteticamente ativa absorvida $(R F A a)$ na média das lavouras de soja no município de Cruz Alta, nas safras 2008/2009 (a) e 2009/2010 (b).

com e sem irrigação respectivamente. Fazendo as devidas compatibilizaçóes de unidades e integrando a RFAa estimada ao longo de todo o ciclo da soja, infere-se que na safra 2009/2010, a cultura absorveu cerca de $1100 \mathrm{MJ} \mathrm{m}^{-2}$, sendo acumuladas $10270 \mathrm{~kg} \mathrm{ha}^{-1}$ de matéria seca nas áreas não irrigadas e $17920 \mathrm{~kg} \mathrm{ha}^{-1}$ nas áreas irrigadas, o que está dentro do esperado para a cultura. É mais um indicativo da potencialidade desta técnica, podendo este tipo de estimativa ser aplicada ao índice de área foliar ou mesmo rendimento de grãos.

Especialmente para a safra 2009/2010, quando não houve interrupção de mediçóes de $R F A i$ na superfície, observa-se que o padrão temporal da $R F A a$ resulta da disponibilidade de radiaçáo incidente e da área foliar (possibilidade de interceptação da radiação pelo aparato fotossintético disponível). Neste trabalho, estes parâmetros foram inferidos, respectivamente pela $R F A i$ e pelo $N D V I$. No início do ciclo houve aumentos similares de RFAa, acompanhando os aumentos de RFAi e do NDVI. Em janeiro, a redução na disponibilidade de radiação, associada à nebulosidade, determinou um aumento menor do que esperado na $R F A a$, mesmo com os incrementos 
observados no NDVI. Este tipo de resposta também foi observado no início de fevereiro. No fim do ciclo, a $R F A a$ novamente mostrou reduçóes, as quais foram associadas às reduçóes em FRFAa e no NDVI.

Os resultados verificados neste trabalho ratificam trabalhos anteriores (Olfssson e EkLundh, 2007; Schuber et al., 2010) e demonstram que técnicas de sensoriamento remoto podem ser usadas para obter uma representação espacial da RFAa pela cultura da soja. Este tipo de informaçáo pode ser muito útil como dado de entrada para a modelagem dos fluxos gasosos em escala regional. A grande vantagem do uso de imagens é a possibilidade de gerar informaçōes espacializadas cobrindo grandes áreas. Tal informação pode ser obtida em tempo "quase real" e, portanto, pode compor sistemas de monitoramento e de modelagem em diferentes áreas de aplicação. Neste trabalho, foi feita a análise somente da área ocupada com soja, necessitando ainda ser verificada a interferência das áreas vizinhas ocupadas por outros tipos de cobertura vegetal sobre elas.

\section{CONCLUSÃO}

A associação entre o $N D V I$ e a fração da radiação fotossinteticamente ativa absorvida ( $F R F A a)$ é consistente e pode ser usada na geração espacial de informaçôes da radiação fotossinteticamente ativa absorvida ( $R F A a)$ para cultura da soja.

O método aplicado às imagens MODIS possibilita o monitoramento da RFAa ao longo de todo o ciclo de desenvolvimento da soja em tempo "quase real" e com baixo custo.

\section{RFERÊNCIAS}

BARET, F.; GUYOT, G. Potentials and limits of vegetation índices of LAI and APAR assessment. Remote Sensing of Environment, v.3, p.161-173, 1991.

FONTANA, D.C.; BERLATO, M.A.; LAUSCHNER, M.H.; MELO, R.W. Modelo de estimativa de rendimento de soja no Estado do Rio Grande do Sul. Pesquisa Agropecuária Brasileira, v.36, p.399-403, 2001.

FRANÇA, S.; BERGAMASCHI, H.; ROSA, L.M.G. Modelagem de crescimento e rendimento de milho em função da radiaçáo fotossinteticamente ativa e do acúmulo de graus-dia, com e sem irrigaçáo. Revista Brasileira de Agrometeorologia, v.7, p.59-66, 1999.

GUSSO, A.; FORMAGGIO, A. R.; RIZZI, R.; ADAMI, M.; ADAMI, M.; RUDORFF, B F T. Soybean crop area estimation by Modis/Evi data. Pesquisa Agropecuária Brasileira, v.47, p.425-435, 2012.

HUETE, A.; DIDAN, K.; MIURA, T.; RODRIGUES, E.P.; GAO, X.; FERREIRA, L.G. Overview of the radiometric and biophysical performance of the MODIS vegetation index. Remote Sensing of Environment, v.83, p.195-213, 2002.

IBGE - INSTITUTO BRASILEIRO DE GEOGRAFIA E ESTATÍSTICA. Levantamento sistemático da produção agrícola. (2011). Disponível em: <www.ibge.gov.br/home/estatistica/ indicadores/agropecuaria/lspa>. Acesso em: 23/2/2011.

INPE - Instituto Nacional de Pesquisas Espaciais. Catálogo de imagens. Disponível em: <http://www.dgi.inpe.br/CDSR/>. Acesso em 10/9/2010.

JUSTICE, C.O. Monitoring east African vegetation using AVHRR data. International Journal of Remote Sensing, v.6, p.1335-1372, 1986

KUMAR, M.; MONTEITH, J. Remote sensing of crop growth In: SMITH, H. (Ed.). Plants and the daylight spectrum. Londres: Academic Press, 1981. p.133-144.

MAPA - Ministério da Agricultura, Pecuária e Abastecimento. Política agrícola. Disponível em: < http://www.agricultura.gov.br > Acesso em 6/9/2012.

MARTORANO, L.G.; FARIA, R.T.; BERGAMASCHI, H.; DALMAGO, G.A. Evaluation of the CROPGROW/DSSAT model performance for simulating plant growth and grain yield of soybeans subjected and no-tillage and conventional systems in the Subtropiccal Southern Brazil. Italian Journal of Agronomy, v.3, p.795-796, 2008.

MELO, R.W.; FONTANA, D.C.; BERLATO, M.A.; DUCATI, J.R. An agrometeorological-spectral model to estimate soybean yield, applied to southern Brazil. International Journal of Remote Sensing, v.29, p.4013-4028, 2008.

MOREIRA, M.A.; RUDORFF, B.F.T.; FELICIO, J.C.; FREITAS, J.G.; TARGA, M.S. Variação espectral e eficiência do uso da radiação fotossinteticamente ativa em ensaio com genótipos de trigo. Bragantia, v.64, p.331-338, 2005.

MÜLLER, A.G.; BERGAMASCHI, H. Eficiências de interceptação, absorção e uso da radiação fotossinteticamente ativa pelo milho (Zea mays L.), em diferentes disponibilidades hídricas e verificação do modelo energético de estimativa da massa seca acumulada. Revista Brasileira de Agrometeorologia, v.13, p.27-33, 2005.

NASA - National Aeronautics and Space Administration. MODIS Images. Disponível em: <reverb.echo.nasa.gov>. Acesso em $5 / 3 / 2011$.

OLFSSON, P.; EKLUNDH, L. Estimation of absorbed PAR across Scandinavia from satellite measurements. Part II: Modeling and evaluating the fractional absorption. Remote Sensing of Environment, v.110, p.240-251, 2007.

OLIVEIRA, L.M.T.; FRANCA, G. B. Variaçôes do parâmetro biofísico FAPAR ao longo do ano e sua utilização na indicação da atividade fotossintética. Revista Brasileira de Cartografia, v.63, p.85-92, 2011.

RADIN, B.; BERGAMASCHI, H.; REISSER JUNIOR, C.; BARNI, N.A. MATZENAUER, R.; DIDONÉ, I.A. Eficiência de uso da radiação fotossinteticamente ativa pela cultura do tomateiro 
em diferentes ambientes. Pesquisa Agropecuária Brasileira, v.38, p.1017-1023, 2003.

RIZZI, R.; RUDORFF, B.F.T. Imagens do sensor MODIS associadas a um modelo agronômico para estimar a produtividade de soja. Pesquisa Agropecuária Brasileira, v. 42, p.73-80, 2007.

ROSEMBACK, R.; FERREIRA, N.J.; SHIMABUKURO, Y.E.; CONFORTE, J.C. Análise da dinâmica da cobertura vegetal na regiáo sul do Brasil a partir de dados MODIS/Terra. Revista Brasileira de Cartografia, v.62, p.401-416, 2010.

SCHUBERT, P.; EKLUNDH, L.; LUND, M.; NILSSON, M. Estimating northern peatland $\mathrm{CO} 2$ exchange from MODIS time series data. Remote Sensing of Environment, v.114, p.1178-1189, 2010.

SELLERS, P.; LOS, S.; TUCKER, C.; JUSTICE, C.O.; DAZLICH, D.; COLLATZ, G. et al. A global $1^{\circ}$ by $1^{\circ}$ NDVI data set for climatic studies, pt 2: The adjustment of the NDVI and generaton of global fields of terrestrial biophysical parameters. International Journal of Remote Sensing, v.15, p.3519-3546, 1994.
SJÖSTRÖM, M.; ARDÖ, J.; ARNETH, A., BOULAIN, N.; CAPPELAERE, B.; EKLUNDH, L.; GRANDCOURT, A.; KUTSCH, W.L.; MERBOLD, L.; NOUVELLON, Y.; SCHOLES, R.J.; SCHUBERT, P.; SEAQUISTA, J.; VEENENDAA, E.M. Exploring the potential of MODIS EVI for modeling gross primary production across African ecosystems. Remote Sensing of Environment, v.115, p.1081-1089, 2011.

SUGAWARA, L. M.; RUDORFF, B F T.; ADAMI, M. Viabilidade de uso de imagens do Landsat em mapeamento de área cultivada com soja no Estado do Paraná. Pesquisa Agropecuária Brasileira, v.43, p.1777-1783, 2008.

SULFLUX - Rede Sul Brasileira de fluxos superficiais e mudança climática. Experimental Sites. Disponível em: <http://www.sulflux. ufsm.br/sulflux>. Acesso em 6/9/2012.

WEBLER, G.; ROBERTI, D.R.; CUADRA, S.V.; MOREIRA, V.S.; COSTA, M.H. RODRIGUES, C.P. Evaluation of a Dynamic Agroecosystem Model (Agro-IBIS) for Soybean in Southern Brazil. Earth Interactions, v.16, p.1-15, 2012. 